\title{
Spontaneous uvula hematoma: an unusual case
}

\author{
Hacer Baran ${ }^{1}$, Ozan Gokdogan ${ }^{2}$ \\ ${ }^{1}$ Departement of Otorhinolaryngology, Medical Park Hospital, Bursa, Turkey \\ ${ }^{2}$ Department of Otorhinolaryngology, Memorial Hospital, Ankara, Turkey
}

\begin{abstract}
Hematomas in upper aerodigestive tract are not rare especially in patients with cardiologic conditions. Without comorbidities, it can also be seen after trauma cases. Sponatenous hematoma is a rare clinical condition that needs detailed evaluation especially for hematologic and immunologic disorders. We describe a case with spontaneus uvula hematoma. We describe a case with spontaneus uvula hematoma, without a history of trauma and anticoagulant therapy. We also discussed the management strategies. This patient with those findings, appears to be the firts case that was published in the English-language literature.
\end{abstract}

Eur Res J 2015;1(2):78-80

Keywords: Spontaneous, hematoma, uvula

\section{Introduction}

In literature there were lingual, uvula hematomas cases after thrombolytic treatment with streptokinase or retro- and parapharyngeal haematoma spontaneously [1-3]. We describe a case of spontaneus uvula hematoma.

\section{Case Presentation}

A 16-year-old man presented with complaint of a foreign body sensation and difficulty in swallowing in the throat. The patient was admitted to the hospital with a foreign body sensation and difficulty in swallowing in the throat. The patient had no history of systemic disease or trauma. His complaints started 1 day ago. There was no recent history of endotracheal intubation or other intraoral trauma.

The patient did not have stridor, dyspnea or a change in vocal tone. The patient had no history of systemic disease or trauma. An enlarged and bruised uvula was noted at oral cavity examination. (Figure 1). Other systemic physical examination of the case was normal. The patient's blood panel, platelet count, coagulation studies and peripheral blood smears were normal.

We drained hematom under local anesthesia with enjector. One cc blood was drained. After that 40 mg PrednolR was injected intravenously.

Address for correspondence:

Ozan Gokdogan, MD, Departement of Otorhinolaryngology, Memorial Health Group Hospital, Ankara, Turkey

Telephone: +90-(505) 5966558 ozangokdogan@gmail.com

Received: 22.12.2014; Accepted: 08.02.2015: Published Online: 04.07.2015 
We observed patient for a day. After the procedure complaints of patients are reduced. We evaluated the patient in the control examination after three days. He had no complaints. (Figure 2)

\section{Discussion}

Hematoma of the uvula, mouth, tongue, sublingual, laryngeal and face have been reported after streptokinase administration or hemophilia $[1,2,4,5]$. In literature one cases was presented with spontaneous haemorrhage into the retropharyngeal and parapharyngeal space secondary to bleeding from a thyroid cyst [3]. Usually a history of anticoagulant therapy or an anatomic pathology were determined the cause of hematoma.

There are reports of hemmorhage into the oral cavity after streptokinase administration when the airway has not been manipulated $[1,3,6]$. Hemorrhage and hematoma of the oral cavity can be fatal [5]. In literature an uvula hematom was determined spontaneusly after streptokinase administration in intubated patient [1]. In our case there are uvula hematoma without a history of trauma, anticoagulant therapy or systemic disease. The first target in the management strategy is to control patient's airway. If intubation is impossible due to upper airway pathologies, emergency tracheotomy may be necessary. After maintaining air way, management of anticoagulation if necessary or drainage of hematoma is the second step of management of upper aerodigestive hematomas. If hematoma of upper aerodigestive tract is not so serious, spontaneous resolution occurs within a few days. Cessation of anticoagulants if possible may help this period.

Surgical drainage may result in some complications such as increased swelling even with complete airway obstruction and post-operative rebleeding.

However there are a few case reports in the management of upper aerodigestive tract hematomas, airway protection, cessation of anticoagulant if necessary and hematoma drainage are the main treatment strategies.

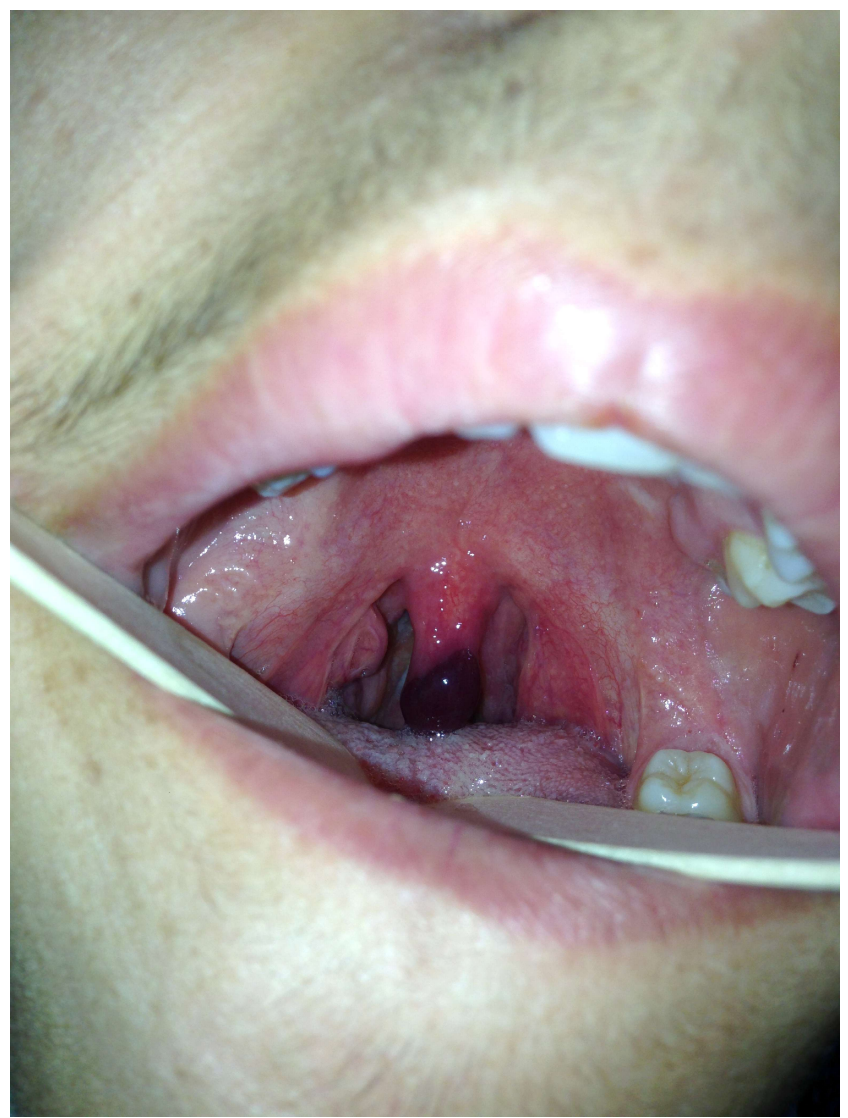

Figure 1. An enlarged and bruised uvula at oral cavity

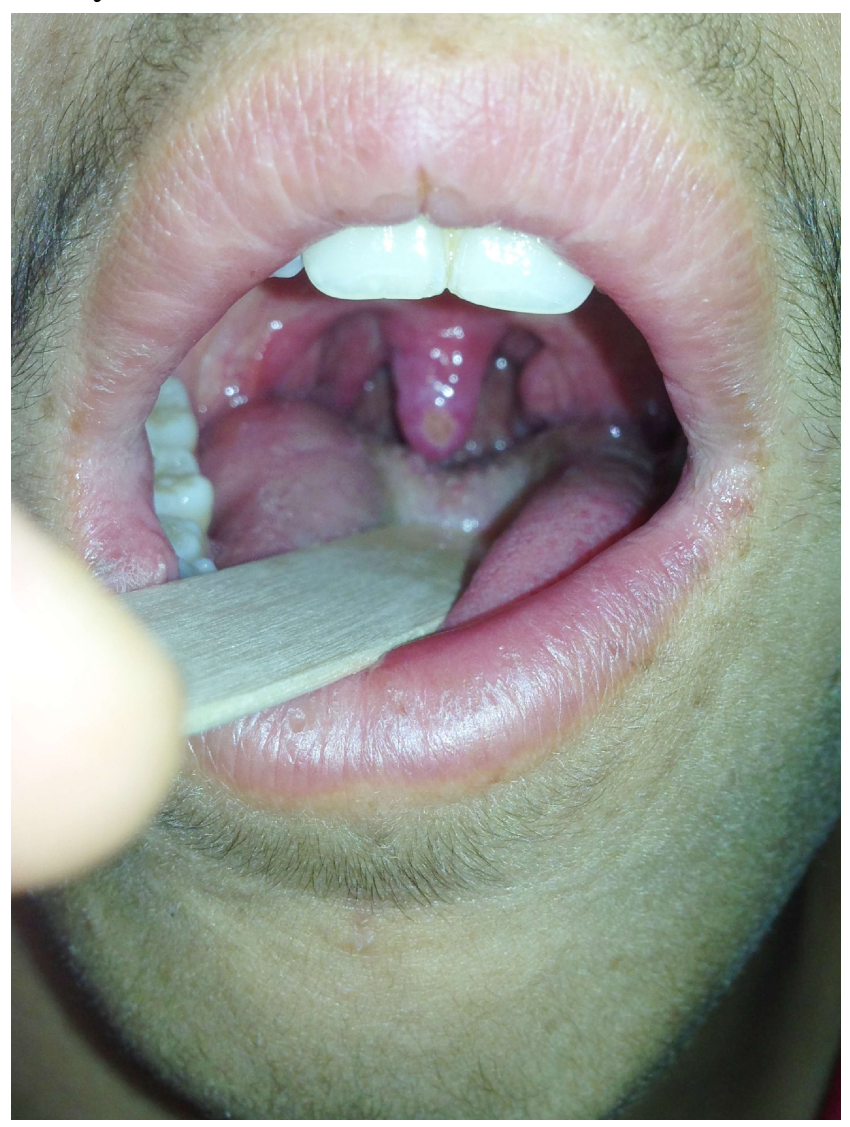

Figure 2. Appearance of the uvula after drainage. 


\section{Conclusion}

Trauma and anticoagulant drug use are the main etiologic factors of upper aerodigestive tract hematomas. The main priority of management strategy in upper airway hematomas is based on airway protection. After airway integrity provided, drainage procedures may be applied.

\section{References}

[1] Gill P, Sadler P. Uvula hematoma: an unusual complication of streptokinase. Anesth Analg. 1999 Aug;89(2):307-8.
[2] Eggers KA, Mason NP. Lingual haematoma following streptokinase therapy [letter]. Anaesthesia. 1994;49:922. [3] Paleri V, Maroju RS, Ali MS, Ruckley RW. Spontaneous retroand parapharyngeal haematoma caused by intrathyroid bleed. J Laryngol Otol. 2002 Oct;116(10):854-8.

[4] Jervis P, Mason JDT, Jones NS. Streptokinase and facial haematoma. Postgrad Med. 1995;71:114 -5.

[5] Kausar H, Gilani JM, Khan OA. No more Doritos and lobster tails: a case report of life-threatening sublingual hematoma. Del Med J. 2009 Jul;81(7):255-8.

[6] Williams PJ, Jani P, McGlashan. Lingual haematoma following treatment with streptokinase and heparin: anaesthetic management. Anaesthesia. 1994;49:417- 8. 